\title{
Survival: A Motivation for Reverse Stock Splits
}

\author{
Frederick Adjei ${ }^{1, *}$, Mavis Adjei ${ }^{2}$ \\ ${ }^{1}$ Economics and Finance Department, Southeast Missouri State University, Cape Girardeau, USA \\ ${ }^{2}$ Marketing Department, SIU Carbondale, Carbondale, USA \\ *Corresponding author
}

\begin{abstract}
This study investigates delisting avoidance on an exchange as a motivation for reverse stock splits. I examine the different motivations for reverse splits for stocks at different pre-split price levels by dividing the sample into two groups, below or equal to \$2, and above \$2. Using a control sample of firms receiving delisting warnings, I find that firms on the brink of delisting, use reverse splits to extend exchange listing time. For firms with a pre-split price above \$2, I find that liquidity enhancement may be the motivation for reverse splits.
\end{abstract}

Keywords: survival reverse stock splits

Cite This Article: Frederick Adjei, and Mavis Adjei, "Survival: A Motivation for Reverse Stock Splits." Journal of Finance and Economics, vol. 5, no. 5 (2017): 204-210. doi: 10.12691/jfe-5-5-2.

\section{Introduction}

A reverse stock split is a reduction in a firm's number of shares outstanding with a proportionate increase in stock price. After a one-for-ten reverse split, each shareholder has one-tenth as many shares, and the firm's number of shares outstanding also decreases by a factor of 0.1 (the reverse split factor). The value of the firm does not change since each share is worth ten times more. Reverse splits, like forward stock splits, are essentially aesthetic without real economic implications. However, forward stock splits frequently increase the average relative tick size resulting in an increase in trading costs as measured by the proportional bid-ask spread, which, in turn, increases dealer incentives to promote the stock [1]. On the other hand, reverse splits lead to an increase in liquidity [2] but receive little attention in financial research, since their features are thought to simply be the opposite of those of forward stock splits. In recent years, some reputable firms, such as AT\&T and Ericsson, have engaged in reverse splits. The contribution of this study is four-fold. First, I investigate the motivation for reverse splits for different pre-split prices. I find that for reverse splits with a pre-split price above $\$ 2$, there is a decrease in trading costs following the event. However for firms with a pre-split price equal to or below \$2, I observe an increase in trading costs. These findings suggest that the motivation for reverse splits for firms with a pre-split price below $\$ 2$ may not be to increase liquidity.

Second, I investigate whether survival, defined as delisting prevention, may be a motivation for reverse splits for firms with a pre-split price below \$2. Using a control sample of firms which receive exchange delisting warnings but do not reverse split, I compare the survival time of the control firms with that of reverse split firms following receipt of delisting warnings. I find that reverse split firms with a pre-split price below $\$ 2$ have significantly longer survival time than control firms following exchange warnings.

Third, using daily dollar trading volume as a proxy for liquidity, I investigate liquidity changes following reverse splits. This is the first study to use dollar trading volume to measure liquidity around stock splits. The dollar trading volume measure allows us to compare pre- and post-split liquidity directly without adjustment for change in postsplit number of shares outstanding. I find a significant increase in liquidity for the NASDAQ subsample. However, when the sample is segregated into the two price levels, no significant change in dollar trading volume is observed in either subsample. I find the insignificant change in liquidity following reverse splits for stocks with a pre-split price less than \$2 particularly interesting, since this buttresses my point about liquidity not being a motivation for reverse splits for stocks priced below $\$ 2$.

Fourth, I investigate whether the post-reverse split return volatility decline is related to trading activity. I find that the decline in return volatility following reverse splits is related to the decrease in trading activity following the reverse split. The rest of the study is organized as follows. Section I discusses the literature review, and section II discusses the hypotheses development. Section III covers the data and methodology. Section IV contains the results and discussion and in section $\mathrm{V}$, the summary and conclusion.

\section{Literature Review}

Several empirical studies present indirect evidence to support the assertion that a reduction in the percentage spread is a motivation for reverse splits [1,3]. Han [2], studying reverse splits, finds an increase in liquidity following the splits. He finds a reduction in the percentage spread, a measure of trading costs. He also finds no empirical support for the assertion that reverse splits 
may be motivated by exchange listing requirements Interestingly, Han does not segregate his sample into price ranges. Consequently, he did not pick up the different motivations for reverse splits at different pre-split prices. I divide my sample into two groups based on price. Kim, Jain, Jiang, McInish, and Wood [4] divide their sample of reverse splits into two groups based on pre-split price, below and above $\$ 5$. Kim et. al. find that firms with a presplit price less that \$5 may have a delisting avoidance motivation, whiles stocks with a pre-split price above $\$ 5$ may be motivated by a quest for higher liquidity. However, Kim et. al. do not provide empirical support for the delisting avoidance motivation. This study provides empirical support for the delisting avoidance motivation by comparing reverse split firms' listing duration to that of control firms following warnings of delisting.

Another motivation for reverse splits is to reduce the number of shareholders to eliminate disclosure requirements [5]. Reverse splits may squeeze minority shareholders out, particularly in states where shareholders are not allowed to hold fractional shares, and this will decrease the cost of servicing shareholders. The enhancement in stock marketability is yet another motive speculated for reverse stock splits. According to Lakonishok and Lev [6], stocks are most marketable in certain price ranges. Demsetz [3] argues that the enhancement in stock marketability will improve liquidity. If the motive for a reverse split is to move the price to an "optimal price range" [7], then the reverse split could enhance the marketability of the stock. West and Brouilette [8] discover that a firm chooses to reverse split in order to boost its image among prospective investors, to enhance its marketability, and to reduce trade execution costs. Hence, shareholders are expected to find reverse splits beneficial and the market is expected to respond favorably to this event. The market generally responds unfavorably to reverse splits, however.

Reverse splits signal negative firm performance and a lack of assurance in the firm's future profitability. According to Spudeck and Moyer [9], reverse splits signal management's lack of confidence in the future performance of the firm. Wooldridge and Chambers [10] further assert that, upon learning of an impending reverse split, shareholders should sell their shares. Desai and Jain [11] find negative abnormal returns following reverse stock splits.

\section{Hypotheses Development}

This section develops the empirical hypotheses surrounding the motivation for reverse stock splits and survival following the event.

\section{A. Motivation for Reverse Stock Splits}

Reasons for reverse stock splits overlap, to some degree, those of regular stock splits. For instance, reverse as well as forward stock splits may be used to move the stock price to an optimal trading price, which, in turn may lead to lower transaction costs for shareholders [1,2].

However, some motives of forward stock splits may not apply to reverse splits. Signaling of good news is a common motive cited for forward stock splits. The argument proposes that forward stock splits decrease information asymmetries either directly by indicating good information that was formerly privately known or by bringing awareness to the firm [12]. With the negative market reaction to reverse splits, signaling may not be a motivation.

For stocks with a pre-split price below $\$ 2$, reverse splits may be a means to stay listed. For example, NASDAQ delists stocks that trade below the minimum bid price of $\$ 1$ for 30 consecutive days and AMEX recommends a reverse split for firms which violate the minimum trading price standard. Reverse splits may save such stocks from being delisted. I argue that firms use reverse splits as a means to remain listed on the exchanges rather than a signaling tool, since reverse splits generally have a negative connotation. If management is hopeful about the future performance of the firm, there is little incentive to artificially increase stock prices. Hence, the announcement of reverse splits is usually interpreted as bad news. Kim, Jain, Jiang, McInish, and Wood [4], assert that reverse splits have a potential of saving a company from being delisted from the exchanges. For example, AMEX advises companies which fail to meet the minimum continued listing price requirement to embark on reverse splits to increase their prices. Clearly, reverse splits can be a survival technique [survival is defined as continued listing on the exchange], especially for low-priced stock.

Reverse splits in which the pre-split price is above \$2 may have a motive other than survival. Such stocks already meet continued listing requirements for price and hence their split may have a liquidity enhancement motive. Jiang, McInish, and Wood (2005) find an increase in liquidity following reverse splits, and this may be a motivation for some companies to reverse split. Hence for companies with a pre-split price above \$2, I conjecture that liquidity improvement may be the motivation for the reverse split.

\section{$B$. Reverse splits and Liquidity}

As stated earlier, reverse splits should result in lower proportional transaction costs and increase liquidity, [2] Barclay, Kandel, and Marx [13] find a significant negative relation between changes in bid-ask spreads and trading volume. One might argue, however, that reverse splits decrease the liquidity of the stock by increasing the price of the stock, reducing affordability to small investors and hence, decreasing the trading volume. For example, after a one-for-five reverse split, the cost of a round-lot becomes five times more expensive and hence, less affordable to small investors. However, pre-split prices are so low that post-split prices are still affordable even by small investor standards, and hence one expects an increase in liquidity following reverse splits. Consistent with Han [2], I hypothesize an increase in liquidity following reverse splits.

\section{Reverse Splits and Volatility}

One of the most baffling anomalies in stock price behavior is the significant increase in the variance of returns starting on the ex-date of stock splits [14]. Furthermore, the variance increase continues for extended periods. There are a number of plausible explanations for this anomaly. According to Amihud and Mendelson [15], two components of the market microstructure, bid-ask bounce and price discreteness, could cause measurement errors leading to a biased estimate of the return variance. Koski [16] examines these components by controlling for 
bid-ask bounce using bid-to-bid prices to compute returns and for price discreteness using different price intervals. Koski's results show that post-split return volatility is neither affected by bid-ask bounce nor price discreteness. French and Foster [14] also conclude that the increase in return volatility following stock splits cannot be explained by price discreteness. Interestingly, a converse phenomenon occurs following reverse stock splits. There is a decline in return volatility as well as a decline in trading activity. I investigate post-reverse split trading activity as a determinant of the post-reverse split return volatility change.

\section{Data and Methodology}

\section{A. Sample}

The sample consists of all reverse splits that occurred between January, 1995 and December, 2004. Reverse split dates are identified using split factors (factor to adjust prices) in CRSP. Stocks with split factors between 0 and 1 are reverse splits and the days that these values occur are assumed to be the ex-reverse split dates. A reverse split factor (RSF) is calculate

$$
R S F=\frac{\text { Post }- \text { Split Shares Outstanding }}{\text { Pre }- \text { Split Shares Outstanding }}
$$

All stocks with 90 days of return data before and after the reverse split are retained. A 90-day pre/post-reverse split window, as used by French and Foster [14], is chosen because it is wide enough to identify transient changes that may occur around the ex-date and it also leaves a window large enough to draw inferences on post-reverse split return variance behavior for the entire sample. Intraday trade and quote data is obtained from the NYSE's Trade and Quote (TAQ) database. Additionally, SEC Edgar files are searched for warnings of exchange delistings. The tick size changed from $\$ 1 / 8$ to $\$ 1 / 16$ on May 7, 1997 for AMEX, June 2, 1997 for NASDAQ, and June 24, 1997 for the NYSE. Next, the NYSE and AMEX switched to decimal pricing on January 29, 2001. The Nasdaq Stock Market decimalized subsequently, on April 9, 2001. To eliminate the effects of the tick size change and the decimalization, reverse splits that had only a pre- or post-split window in these periods were eliminated. The resulting sample consists of 258 reverse splits and this is divided into two groups according to the pre-split stock price of the stock, below or equal to $\$ 2$, and above $\$ 2$.

\section{B. Control Sample}

Firms which reverse split after receiving delisting warnings are matched with control firms which receive delisting warnings but do not embark on reverse splits. Reverse split firms are matched with control firms based on time of warnings, firm size, and exchange. These firms are then observed for 36 months following the warnings to find out how long they remain listed on the exchange, survival time. For firms that last longer than 36 months, their survival time is set to 36 months.

\section{Liquidity measures}

Trading volume [6,7] and the bid-ask spread $[17,18]$ are proxies for stock liquidity. Ceteris paribus, higher trading volume and/or lower bid-ask spread indicate higher stock liquidity. Dollar trading volume, number of shares multiplied by stock price, is also used as a measure of liquidity. Using dollar trading volume eliminates the need to adjust post-split shares by the split factor.

\section{Volatility Regression Model}

The variance of continuously compounded daily stock returns is used as a proxy for return volatility. The continuously compounded daily stock return is calculated as:

$$
R_{c i}=\operatorname{In}\left(1+R_{i}\right)
$$

where $R_{c i}$ is the continuously compounded daily return for stock $i$ and $R_{i}$ is the ordinary daily return for stock $i$, using bid to bid returns. The daily stock returns are adjusted by subtracting the CRSP equally weighted index return to ensure that the returns are not affected by any trends in market volatility over the pre/post-reverse split window.

Several factors impact the volatility of returns. If any of these factors changes with a reverse split, then volatility will change as well. According to French and Foster [14], one potential problem with using daily returns computed from closing prices is that a part of the observed variance may be due to bid-ask bounce. Bid-ask bounce occurs when the closing price on one day is at the quoted bid and is followed the subsequent day with a closing price at the ask. To eliminate bid-ask bounce, pre-reverse split and post-reverse split returns are computed using bid-to-bid returns $[16,19]$.

As documented by French and Foster [14], the split factor and the post-reverse split price may also affect volatility changes. The trading range hypothesis postulates that firms like to keep their stock prices within particular price ranges, close to the industry median, reflecting the belief that greater liquidity exists within certain price ranges. Consequently, RSFs are generally chosen so that the resulting post-reverse split price will be close to the industry median. The choice of an RSF may influence post-reverse split abnormal returns. I test whether the RSF has an impact on the variance of the returns. Additionally, according to Desai, Nimalendran, and Venkataraman [19], the level of post-reverse split price may also influence variance changes. I control for price, by including the mean post-split price for the 90 days after the reverse split, in the regression. To control for all these factors and test the effect of trading activity on the volatility of post-reverse split returns the following regression, as estimated by French and Foster [14], is estimated for all stocks:

$$
\begin{aligned}
& \operatorname{In}\left(\frac{\sigma^{2}{ }_{i, \text { post }}}{\sigma^{2}{ }_{i, \text { pre }}}\right) \\
& =\beta_{0}+\beta_{1} \operatorname{In}\left(\frac{T_{i, \text { post }}}{T_{i, \text { pre }}}\right)+\beta_{2} R S F_{i}+\beta_{3} P_{i}+\varepsilon_{i}
\end{aligned}
$$

where $\sigma^{2}$ is the variance of stock returns, $T$ is number of trades, post represents the post-reverse split data, pre is for pre-reverse split data, and $P$ is the mean post-reverse split stock price. The regression relates the percentage change in variance to the percentage change in the number of trades after the reverse split, the RSF, and the post-reverse split stock price. If the coefficient for $\operatorname{In}\left(\frac{T_{i}, \text { post }}{T_{i}, \text { pre }}\right), \beta_{1}$ is 
significantly positive, then the post-reverse split volatility is positively influenced by the trading activity.

\section{Results and Discussion}

Table 1 depicts the sample characteristics. Panel A shows a frequency of the reverse splits for each reverse split factor (RSF) range. Panel B depicts the mean prices of stocks before and after the reverse splits. Considering all the sample stocks, the pre-reverse split price is $\$ 1.69$ and the post-reverse split price is $\$ 6.29$. NASDAQ stocks have the lowest pre-reverse split prices with an average of $\$ 1.28$. The mean post-reverse split price for the NASDAQ stocks is $\$ 4.65$. The NYSE/AMEX subsample has mean pre- and post-split price of $\$ 2.79$ and $\$ 10.68$ respectively.

The number of firms that received warnings from the exchange for not meeting continued listing requirements is depicted in Table 2. For firms with a pre-split price below \$2, 140 NASDAQ and 25 AMEX firms received warnings within 90 days before the reverse split. None of the firms with a pre-split price above $\$ 2$ received warnings.

The survival time of firms following exchange warnings is depicted in Table 3. For firms embarking on reverse splits following the warnings, the mean survival time is 30.32 months. The mean survival time for the control firms is 6.72 and the difference in mean survival time between reverse split firms and the control firms is significant at the $1 \%$ level. Additionally, only $21.8 \%$ of reverse split firms are subsequently delisted within the 36 month period compared to a whopping $98.2 \%$ of control firms delisted in the same period. Evidently, reverse splits save firms from delisting.

Table 4 depicts the daily dollar trading volume. There is a significant increase in mean dollar trade size for the entire sample following reverse splits. For the NASDAQ subsample, there is a significant increase in the mean daily dollar trading volume following the reverse split. These results are consistent with an increase in liquidity following reverse splits as discovered by Han [2]. Table 5 shows stock liquidity as measured by daily dollar trading volume. No significant change in liquidity is observed.

Table 6 depicts the changes in percentage spread and percentage effective spread following the reverse splits. For the entire sample, as well as the NASDAQ subsample, there is a significant increase in percentage effective spread, signifying an increase in trading costs following reverse splits. The NYSE/AMEX subsample tells an entirely different story, however. There is a decrease in both percentage spread and percentage effective spread for the NYSE/AMEX subsample, signifying a reduction in trading costs following reverse splits.

The results shown in Table 7 indicate that for reverse splits with a pre-split price below \$2, the percentage effective spread significantly increases following the split. For reverse splits with a pre-split price above \$2, there is a significant decrease in percentage spread following the split. These findings are consistent with an increase in trading costs for reverse splits with a pre-split price below $\$ 2$ and a decrease in trading costs for reverse splits with a pre-split price above $\$ 2$.

Table 8 depicts the mean pre-and post-reverse split return variances by exchange and also for the two price ranges. There is a significant decrease in return variance following reverse splits for the NYSE/AMEX subsample.

Table 9 presents the results of the volatility regression model for the entire sample and also by exchange. If the coefficient for $\operatorname{In}\left(\frac{T_{i}, \text { post }}{T_{i}, \text { pre }}\right), \beta_{1}$ is significantly positive, then the post-reverse split volatility is positively influenced by the trading activity. $\beta_{1}$ is statistically significant at the $1 \%$ level for the entire sample and also for the NASDAQ subsample, indicating that the decline in return volatility following reverse splits is related to the decrease in trading activity following the reverse split.

Table 1. Sample Characteristics

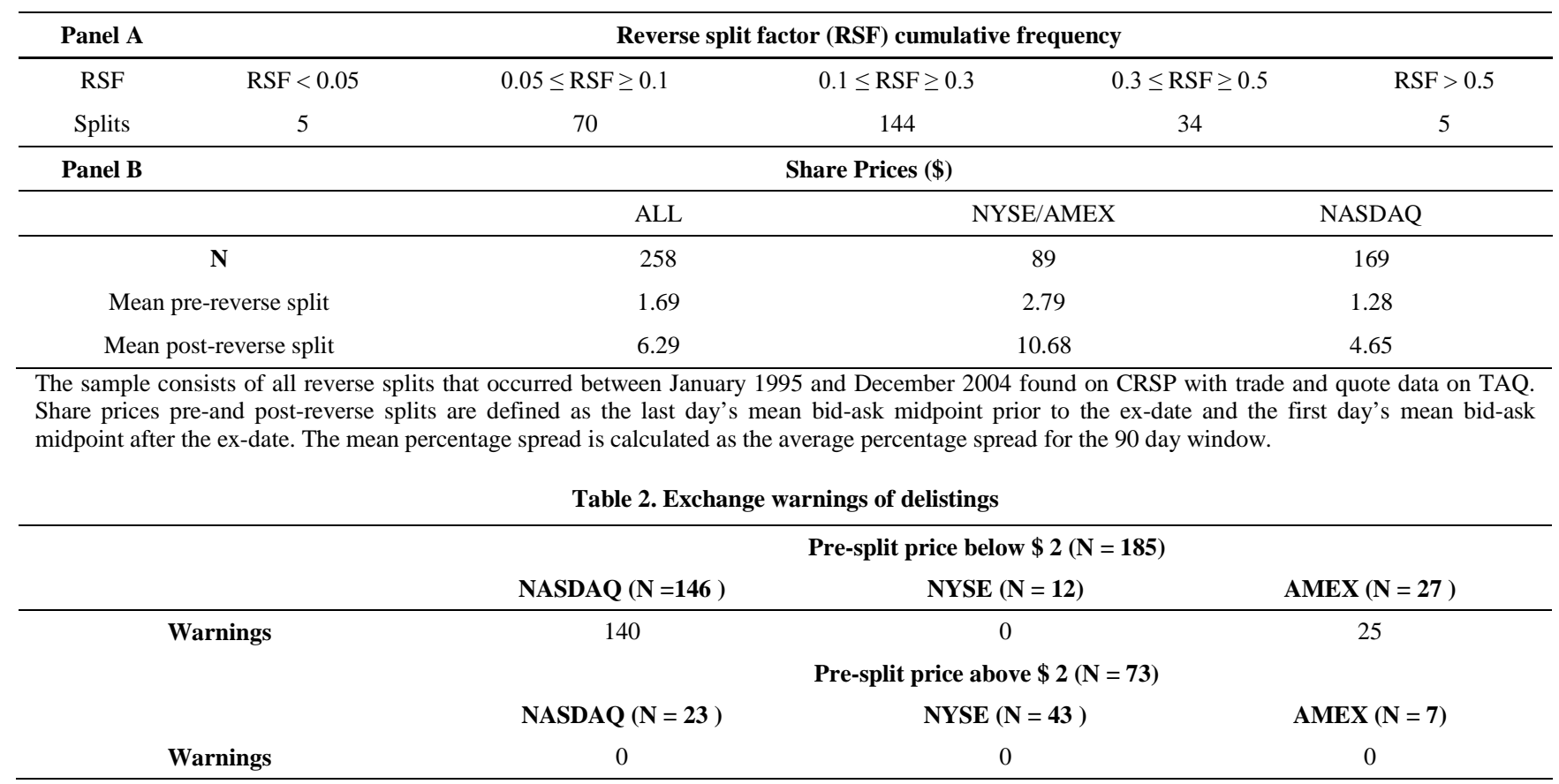


Table 3. Reverse splits and survival

\begin{tabular}{|c|c|c|c|c|}
\hline & Mean & Median & Standard Deviation & Delisted Firms (\%) \\
\hline Reverse Split Firms (N=165) & 30.32 & 36 & 7.99 & $36(21.8)$ \\
\hline Control firms $(\mathrm{N}=165)$ & 6.72 & 5.00 & 6.14 & $162(98.2)$ \\
\hline Difference (Reverse split minus control) & 23.60 & & & $-126(-76.4)$ \\
\hline t-statistic & $25.14^{* * *}$ & & & \\
\hline
\end{tabular}

Comparison of listing time (in months) of reverse split firms versus control firms following exchange warnings of delisting.

* Indicates statistical significance at the 0.10 level.

** Indicates statistical significance at the 0.05 level.

*** Indicates statistical significance at the 0.01 level.

Table 4. Stock liquidity as measured by daily dollar trading volume

\begin{tabular}{lcccc}
\hline Panel A & \multicolumn{3}{c}{ ALL (N = 258) } \\
\hline & Pre-split & Post-split & Difference (Post - Pre) & t - statistic \\
\hline Mean Dollar Trade Size & 6246.50 & 9954.50 & 3708 & $11.16^{* * *}$ \\
Mean Daily Dollar Volume (millions) & 1.97 & 2.18 & 0.209 & 1.20 \\
Mean Daily Number of Trades & 224.48 & 119.26 & -105.23 & $-12.35^{* * *}$ \\
\hline Panel B & \multicolumn{2}{c}{ NYSE/AMEX (N = 89) } & t - statistic \\
\hline & Pre-split & Post-split & Difference (Post - Pre) & $6.77^{* * *}$ \\
\hline Mean Dollar Trade Size & 16410 & 26254 & 9843 & -0.31 \\
Mean Daily Dollar Volume (millions) & 8.20 & 7.91 & -0.29 & $-5.33^{* * *}$ \\
Mean Daily Number of Trades & 240.73 & 148.12 & -92.61 & $\mathbf{t}$ \\
\hline Panel C & \multicolumn{4}{c}{ statistic } \\
\hline & Pre-split & Post-split & Difference (Post - Pre) & $10.29^{* * *}$ \\
\hline Mean Dollar Trade Size & 3571.50 & 5764.30 & 2193 & $3.92^{* * *}$ \\
Mean Daily Dollar Volume (millions) & 0.65 & 0.86 & 0.21 & $-11.18^{* * *}$ \\
Mean Daily Number of Trades & 224.82 & 115.43 & -109.39 & (169)
\end{tabular}

Liquidity is measured by the daily dollar trading volume. Difference = Mean post-reverse split volume minus mean pre-reverse split volume.

* Indicates statistical significance at the 0.10 level.

** Indicates statistical significance at the 0.05 level.

*** Indicates statistical significance at the 0.01 level.

Table 5. Stock liquidity as measured by daily dollar trading volume by pre-split price levels

\begin{tabular}{lcccc}
\hline Panel A & \multicolumn{2}{c}{ Pre-split price below \$ 2 (N = 185) } \\
\hline & Pre-split & Post-split & Difference (Post - Pre) & t - statistic \\
\hline Mean Dollar Trade Size & 3927.00 & 6249.20 & 2322.20 & $6.37^{* * *}$ \\
Mean Daily Dollar Volume (millions) & 0.30 & 0.52 & 0.22 & $4.72^{* * *}$ \\
Mean Daily Number of Trades & 64.37 & 35.26 & -29.11 & $-10.33^{* * *}$ \\
\hline Panel B & \multicolumn{2}{c}{ Pre-split price above \$ 2 (N = 73) } & t - statistic \\
\hline & Pre-split & Post-split & Difference (Post - Pre) & $9.53^{* * *}$ \\
\hline Mean Dollar Trade Size & 7692.60 & 12355.00 & 4662.40 & 0.86 \\
Mean Daily Dollar Volume (millions) & 3.01 & 3.26 & 0.25 & $-11.06^{* * *}$ \\
Mean Daily Number of Trades & 324.32 & 173.68 & -150.64 & \\
\hline
\end{tabular}

The pre- and post-split mean dollar trading volume is estimated for the two pre-split price levels.

* Indicates statistical significance at the 0.10 level.

** Indicates statistical significance at the 0.05 level.

*** Indicates statistical significance at the 0.01 level.

Table 6. Changes in percentage bid-ask spreads and percentage effective spreads around reverse splits

\begin{tabular}{lcccc}
\hline Panel A & \multicolumn{3}{c}{ ALL (N = 258) } \\
\hline & Pre-split & Post-split & Difference (Post - Pre) & t - statistic \\
\hline Percentage Spread & 0.086 & 0.085 & -0.001 & -0.62 \\
Percentage Effective Spread & 0.074 & 0.629 & 0.555 & $6.65^{* * *}$ \\
\hline Panel B & \multicolumn{2}{c}{ NYSE/AMEX (N = 89) } \\
\hline & Pre-split & Post-split & Difference (Post - Pre) & t - statistic \\
\hline Percentage Spread & 0.086 & 0.062 & -0.024 & $-9.78^{* * *}$ \\
Percentage Effective Spread & 0.058 & 0.043 & -0.015 & $-2.58^{* * *}$ \\
\hline Panel C & \multicolumn{2}{c}{ NASDAQ (N = 169) } & t - statistic \\
\hline & Pre-split & Post-split & Difference (Post - Pre) & $2.85^{* * *}$ \\
\hline Percentage Spread & 0.087 & 0.098 & 0.011 & $6.70^{* * *}$ \\
Percentage Effective Spread & 0.082 & 0.987 & 0.905 &
\end{tabular}

The mean percentage bid-ask spread for the pre- and post-split periods are reported here.

* Indicates statistical significance at the 0.10 level.

** Indicates statistical significance at the 0.05 level.

*** Indicates statistical significance at the 0.01 level. 
Table 7. Changes in bid-ask spreads around reverse splits by price levels

\begin{tabular}{lcccc}
\hline Panel A & \multicolumn{4}{c}{ Pre-split price below \$ 2 (N = 185) } \\
\hline & Pre-split & Post-split & Difference (Post - Pre) & t - statistic \\
\hline Percentage Spread & 0.092 & 0.097 & 0.005 & 1.49 \\
Percentage Effective Spread & 0.080 & 0.770 & 0.690 & $6.50^{* * *}$ \\
\hline Panel B & \multicolumn{4}{c}{ Pre-split price above \$ 2 (N = 73) } \\
\hline & Pre-split & Post-split & Difference (Post - Pre) & t - statistic \\
\hline Percentage Spread & 0.064 & 0.038 & -0.026 & $-10.83^{* * *}$ \\
Percentage Effective Spread & 0.048 & 0.092 & 0.044 & 1.38 \\
\hline
\end{tabular}

The mean bid-ask spread for the pre- and post-split periods for the two price levels.

* Indicates statistical significance at the 0.10 level.

** Indicates statistical significance at the 0.05 level.

*** Indicates statistical significance at the 0.01 level.

Table 8. Return Volatility

\begin{tabular}{ccccc}
\hline Panel A & Pre-split & Post-split & Difference (Post - Pre) & t - statistic \\
\hline ALL & 0.0157 & 0.0081 & -0.0076 & -1.30 \\
NYSE/AMEX & 0.0044 & 0.0019 & -0.0025 & $-3.68^{* * *}$ \\
NASDAQ & 0.0195 & 0.0101 & -0.0093 & -1.20 \\
\hline Panel B & & Price Divisions & -1.12 \\
Below \$ 2 & 0.0331 & 0.0154 & -0.0176 & -3.16 \\
Above \$ 2 & 0.0056 & 0.0038 & -0.0018 & \\
\hline
\end{tabular}

Return variances are computed using daily closing bid prices 90 days before and 90 days after the reverse split date and converting them to continuously compounded returns. Tests represent a difference from zero for the test of increase in mean variance (mean post-reverse split return variance minus mean pre-reverse split return variance).

* Indicates statistical significance at the 0.10 level.

** Indicates statistical significance at the 0.05 level.

*** Indicates statistical significance at the 0.01 level.

Table 9. Regression examining the effect of the decrease in trades on the variance of post-reverse split returns

\begin{tabular}{lccc}
\hline & ALL $(\mathrm{N}=258)$ & NYSE/ AMEX $(\mathrm{N}=89)$ & NASDAQ (N=169) \\
\hline$\beta_{0}$ & $-0.46^{* * *}$ & $-1.54^{* * *}$ & -0.15 \\
$\beta_{1}$ & $0.31^{* * *}$ & -0.01 & $0.45^{* * *}$ \\
$\beta_{2}$ & 0.59 & $3.07^{* * *}$ & -0.40 \\
$\beta_{3}$ & $-0.01^{*}$ & -0.02 & -0.01 \\
$\mathrm{R}^{2}$ & 0.1246 & 0.3286 & 0.1990 \\
\hline
\end{tabular}

Stock returns were computed using daily closing bid prices 90 days before and 90 days after the ex-date. Regression:

$\operatorname{In}\left(\frac{\sigma_{i}^{2}, \text { post }}{\sigma^{2}, \text { pre }}\right)=\beta_{0}+\beta_{1} \operatorname{In}\left(\frac{T_{i}, \text { post }}{T_{i}, \text { pre }}\right)+\beta_{2} R S F_{i}+\beta_{3} P_{i}+\varepsilon_{i}$

* Indicates statistical significance at the 0.10 level.

** Indicates statistical significance at the 0.05 level.

*** Indicates statistical significance at the 0.01 level.

\section{Conclusion}

This study investigates the motivation for reverse splits and examines changes in return volatility, liquidity, and transaction costs following reverse splits. The findings are the following.

First, reverse splits on NASDAQ and AMEX may be motivated by delisting avoidance, especially for firms with a pre-split price below $\$ 2$. This finding is different from that of Han [2], who finds that most reverse splits are not dictated by exchange regulations. Han, however, does not divide his sample by price and this may explain why he does not find support for the delisting avoidance motivation.

Second, an increase in liquidity for reverse splits with a pre-split price above $\$ 2$ is observed. The assertion, by Kim, Jain, Jiang, McInish, and Wood [4], that the motivation for reverse splits may be determined by the pre-split price, is supported by this finding. Reverse splits with a pre-split price below $\$ 2$ may be motivated by delisting avoidance whiles reverse splits with a pre-split price above $\$ 2$ may be motivated by a quest for liquidity enhancement.

Third, the decline in return volatility following reverse stock splits is associated with a decline in the daily number of trades. This result may explain the anomalous behavior of stock prices following stock splits and reverse stock splits: the increase (decrease) in volatility of returns following stock splits (reverse stock splits).

Fourth, there is an increase in trading costs following reverse splits, for the NASDAQ subsample as well as for stocks with a pre-split price below $\$ 2$. For such firms, it is evident that liquidity enhancement is not a motivation for their reverse splits. I argue that such firms may be driven to reverse splits by the quest to meet exchange listing requirements, and that may explain why they reverse split despite the increase in trading costs following reverse splits. For the NYSE/AMEX subsample as well as the 
stocks with a pre-split price above \$2, the finding of a decrease in trading costs supports my earlier contention that such firms may be motivated by a quest for liquidity enhancement.

My conclusions on reverse split motivations rest on the assumption that firms embarking on reverse splits are fully aware of the liquidity changes for different pre-split price ranges following reverse splits. Hence if a firm reverse splits despite the potential decrease in liquidity, it is reasonable to assume that the reason for the reverse split is not liquidity enhancement.

The decrease in return volatility following reverse splits was puzzling. However, my results imply that a contributing factor is the number of trades. According to French and Foster [14], trading activity is directly related to return volatility. Hence, the decrease in the number of trades following reverse splits may be related to the decrease in return volatility following reverse splits.

In conclusion, the results indicate that the motivation for reverse stock splits is different for different pre-split price ranges. Survival may be the motivation for reverse splits with pre-split price below $\$ 2$ and liquidity enhancement, the motivation for reverse splits with presplit price above \$2. My findings offer new insights into the motivations reverse stock splits.

\section{References}

[1] Schultz, Paul, 2000. Stock Splits, Tick Size, and Sponsorship, Journal of Finance 55, 429-50.

[2] Han, Ki C., 1995. The effects of reverse splits on the liquidity of the stock, Journal of Financial and Quantitative Analysis 30, 159-169.

[3] Demsetz, Harold, 1968. The cost of transacting, Quarterly Journal of Economics 83, 35-53.

[4] Kim, Jang C., Pankaj K. Jain, Christine Jiang, Thomas McInish, and Robert A. Wood, 2005. Reverse Stock Splits, working paper.

[5] Peterson, David R., and Pamela P. Peterson, 1992. A further understanding of stock distributions: The case of reverse stock splits , Journal of Financial Research 15, 189-205.

[6] Lamoureaux, Christopher. G., and Percy Poon, 1987. The Market Reaction to Stock Splits, Journal of Finance 42, 1347-1370.

[7] Lakonishok, Josef, and Baruch Lev, 1987. Stock Splits and Stock Dividends: Why, Who, and When, Journal of Finance 42, 913-932.

[8] West, Richard R., and Andrew B. Bouilette, 1970. Reverse Stock Splits...Harbinger of Bad Times or Valid Management Technique, Financial Executive 38, 12-17.

[9] Spudeck, Raymond E., and Charles R. Moyer, 1985. Reverse Splits and Shareholder Wealth: The Impact of Commissions, Financial Management 14, 52-56.

[10] Woolridge, Randall J., and Donald R. Chambers, 1983. Reverse Split and Shareholder Wealth, Financial Management 12, 5-15.

[11] Desai, Hemang, and Prem C. Jain, 1997. Long-run common stock returns following stock splits and reverse splits, Journal of Business 70(3), 409-433.
[12] Brennan, Michael J., and Thomas E. Copeland, 1988. Stock Splits, Stock Prices, and Transactions Costs, Journal of Financial Economics 22, 83-101.

[13] Barclay, Michael J., Eugene Kandel, and Leslie M. Marx, 1998. The Effects of Transaction Costs on Stock Prices and Trading Volume, Journal of Financial Intermediation 7, 130-150.

[14] French, Dan. W., and Taylor W. Foster, 2002. Does price discreteness affect the increase in return volatility following stock splits?, The Financial Review 37, 281-294.

[15] Amihud, Yakov, and Haim Mendelson, 1987. Trading mechanisms and stock returns: an empirical investigation, Journal of Finance 42, 533-553.

[16] Koski, Jennifer L., 1998. Measurement Effects and the Variance of Returns After Stock Splits and Stock Dividends, Review of Financial Studies 11, 143-162.

[17] Amihud, Yakov, and Haim Mendelson, 1988. Liquidity and Asset Prices: Financial Management Implications, Financial Management 17, 5-15.

[18] Conroy, Robert. M., Robert S. Harris, and Bruce A. Benet, 1990. The Effects of Stock Splits on Bid-Ask Spreads, Journal of Finance 45, 1285-1295.

[19] Desai, Anand S., Mahendrarajah Nimalendran, and Subu Venkataraman, 1998. Changes in Trading Activity Following Stock Splits and Their Effect on Volatility and the Adverse Information Component of the Bid-Ask Spread, Journal of Financial Research 21, 159-183.

[20] Angel, James J., 1997. Tick Size, Share Price and Stock Splits, Journal of Finance 52, 655-681.

[21] Blume, Marshall E., and Michael A. Goldstein, 1997. Quotes, Order Flow, and Price Discovery, Journal of Finance 52, 221-244.

[22] Dubofsky, David A., 1991. Volatility Increases Subsequent to NYSE and AMEX Stock Splits, Journal of Finance 46, 421-31.

[23] Dubofsky, David A., and Dan W. French, 1988. Share Price Level and Risk: Implications for Financial Management, Managerial Finance 14, 6-16.

[24] Duggal, Rakesh and James A. Millar, 1999. Institutional ownership and firm performance: The case of bidder returns, Journal of Corporate Finance 5, 103-117.

[25] Easley, David, and Maureen O'Hara, 1987. Price, Trade Size, and Information in Securities Markets, Journal of Financial Economics 19, 193-212.

[26] Easley, David, Nicholas M. Kiefer, and Maureen O'Hara, 1996. Cream-Skimming or Profit-Sharing? The Curious Role of Purchased Order Flow, Journal of Finance 51, 811-833.

[27] Ellis, Katrina, Roni Michaely, and Maureen O'Hara, 2000. The Accuracy of Trade Classification Rules: Evidence from Nasdaq, Journal of Financial \& Quantitative Analysis 35(4), 529-552.

[28] Ikeberry, David L., Graeme Rankine, and Earl K. Stice, 1996. What do Stock Splits Really Signal?, Journal of Financial and Quantitative Analysis 31, 357-375.

[29] Kryzanowski, Lawrence, and Hao Zhang, 1996. Trading Patterns of Small and Large Traders Around Stock Split Ex-Dates, Journal of Financial Research 19, 75-91.

[30] Maloney, Michael T., and Harold J. Mulherin, 1992. The Effects of Splitting on the Ex: A Microstructure Reconciliation, Financial Management 21, 44-59.

[31] Ohlson, James A., and Stephen H. Penman, 1985. Volatility Increases Subsequent to Stock Splits: An Empirical Aberration, Journal of Financial Economics 14, 251-266.

[32] Powell, Gary E., and Kent H. Baker, 1993/1994. The Effects of Stock Splits on the Ownership Mix of a Firm, Review of Financial Economics 3, 70-88. 